\title{
Review Article \\ Soluble Urokinase Receptors in Focal Segmental Glomerulosclerosis: A Review on the Scientific Point of View
}

\author{
Andreas Kronbichler, ${ }^{1}$ Moin A. Saleem, ${ }^{2}$ Björn Meijers, ${ }^{3}$ and Jae Il Shin ${ }^{4}$ \\ ${ }^{1}$ Medical University Innsbruck, Anichstraße 35, 6020 Innsbruck, Austria \\ ${ }^{2}$ Children's and Academic Renal Unit, University of Bristol, Dorothy Hodgkin Building, Bristol BS2 8BJ, UK \\ ${ }^{3}$ Department of Microbiology and Immunology, KU Leuven and Department of Nephrology, UZ Leuven, 3000 Leuven, Belgium \\ ${ }^{4}$ Department of Pediatric Nephrology, Yonsei University College of Medicine, Severance Children's Hospital, \\ Seoul 120-752, Republic of Korea
}

Correspondence should be addressed to Jae Il Shin; shinji@yuhs.ac

Received 28 March 2016; Accepted 12 June 2016

Academic Editor: Federico Bussolino

Copyright ( $\odot 2016$ Andreas Kronbichler et al. This is an open access article distributed under the Creative Commons Attribution License, which permits unrestricted use, distribution, and reproduction in any medium, provided the original work is properly cited.

Focal segmental glomerulosclerosis (FSGS) is one of the primary glomerular disorders in both children and adults which can progress to end-stage renal failure. Although there are genetic and secondary causes, circulating factors have also been regarded as an important factor in the pathogenesis of FSGS, because about $40 \%$ of the patients with FSGS have recurrence after renal transplantation. Soluble urokinase-type plasminogen activator receptor (suPAR) is a soluble form of uPAR, which is a membranebound protein linked to GPI in various immunologically active cells, including podocytes. It has recently been suggested as a potential circulating factor in FSGS by in vitro podocyte experiments, in vivo mice models, and human studies. However, there have also been controversies on this issue, because subsequent studies showed conflicting results. suPAR levels were also increased in patients with other glomerular diseases and were inversely correlated with estimated glomerular filtration rate. Nevertheless, there has been no balanced review on this issue. In this review, we compare the conflicting data on the involvement of suPAR in the pathogenesis of FSGS and shed light on interpretation by taking into account many points and the potential variables and confounders influencing serum suPAR levels.

\section{Background}

Focal segmental glomerulosclerosis (FSGS) is a primary glomerular disorder with $50 \%$ of patients progressing to endstage renal disease (ESRD) in those unresponsive to treatment [1-3]. FSGS can be divided into primary and secondary forms, but overlap of clinical and histologic features hampers differentiation in some cases [2]. It is considered to be a lesion with diverse clinical features and different pathophysiologic mechanisms and response to treatment [1-3].

Recent evidence shows that FSGS is mainly a "podocytopathy" with several podocyte-related molecules implicated in development and course of the disease, which is supported by insights into genetics from hereditary forms [4-6]. Circulating factors may be directly implicated in the pathogenesis of FSGS, since about $40 \%$ of the patients with primary FSGS have recurrence after kidney transplantation (KT), which may be higher in children than in adults, and significant progress of their pivotal role in the pathogenesis of primary FSGS has been achieved recently $[7,8]$.

Soluble urokinase-type plasminogen activator receptor (suPAR) has recently been suggested as a potential circulating factor in FSGS [9-13]. However, there have also been controversies on this issue, because suPAR levels were also increased in those with other glomerular diseases and were inversely correlated with estimated glomerular filtration rate (GFR) [14-24].

To resolve these discrepancies, we discuss current knowledge regarding the role of suPAR in the pathogenesis of primary FSGS and compare the conflicting data on this issue by taking into account the potential variables influencing serum suPAR levels with a balanced review. 


\section{The Role of Circulating Permeability Factors in FSGS}

A role of a circulating factor in the etiopathogenesis of FSGS has first been proposed in 1972, when Hoyer and colleagues described a case series of patients with recurrent FSGS after KT [25]. Risk factors for disease recurrence include younger age, heavy proteinuria, higher baseline creatinine at the onset of the disease, and rapid progression to ESRD [26, 27]. Biopsies obtained from patients with recurrent FSGS resemble the same histologic subtype in a majority of patients. Plasmapheresis can remove the circulating factor and achieve remission in a subset of children and adults with FSGS [26, 28].

The putative circulating factor of patients with recurrent FSGS appeared to be bound to protein A and hydrophobicinteraction columns [29] and further investigations suggested the molecular mass of this factor to be around $30-50 \mathrm{kDa}$. Injection of supernatant from FSGS sera revealed threefold increased proteinuria in rats after 6 to 24 hours [30].

Onset of proteinuria after exposure to the circulatory factor could be influenced by several components, that is, apolipoproteins which might prevent glomerular albumin permeability after incubation with FSGS sera [31]. Undefined components of normal sera could prevent the increase of glomerular albumin permeability in cultured rat glomeruli [32]. Likewise, application of galactose might diminish glomerular albumin permeability in recurrent FSGS, indicating high affinity of the circulating factor for galactose [33, 34].

Transmission of the glomerular permeability factor from a mother to her unborn child further highlights the pathogenic role of a circulating permeability factor [35]. There have been several factors which have been proposed as potential candidates in the pathogenesis of primary FSGS such as vasodilator stimulated phosphoprotein (VASP) [36] or cardiotrophin-like-cytokine-1 (CLC-1) [7, 37]. Although not proved in FSGS, protein tyrosine phosphatase receptor$\mathrm{O}$ (PTPRO) was suggested to increase glomerular albumin permeability $[7,37]$. suPAR has recently been suggested as a potential circulating factor in FSGS by Wei et al. [9].

\section{UPAR and sUPAR}

The urokinase-type plasminogen activator (uPA) system is composed of a protease, a receptor (UPAR), and inhibitors [38]. uPAR was cloned in 1990 [39] and is a membrane-bound $45-55 \mathrm{kDa}$ protein with three domains $\left(\mathrm{D}_{\mathrm{I}}, \mathrm{D}_{\mathrm{II}}\right.$, and $\left.\mathrm{D}_{\mathrm{III}}\right)$ linked to glycosylphosphatidylinositol (GPI) [38]. It is present in various immunologically active cells, such as neutrophils, lymphocytes, monocytes, macrophages, activated $\mathrm{T}$ cells, endothelial cells, megakaryocytes, tumor cells, and podocytes (Figure 1) [9, 38, 40-43]. uPAR can bind to various ligands such as uPA, vitronectin, and integrins [44]. Upon binding of uPA to its receptor (UPAR) it mediates various cellular activities such as adhesion, migration, differentiation, and proliferation [38]. In podocytes, UPAR is one of the pathways capable of activating $\alpha \mathrm{v} \beta_{3}$ integrin promoting cell motility and activation of small GTPases, such as Cdc42 and Racl, which can lead to podocyte contraction, shifting from a stationary to motile phenotype and leading to foot process effacement and proteinuria (Figure 1) [45].
If UPAR is cleaved from the cell surface, a soluble form of UPAR (suPAR) is released [38, 46]. Full-length suPAR $\left(\right.$ suPAR $\left._{\mathrm{I}-\mathrm{III}}\right)$ can be cleaved into another two soluble forms with different biologic properties, suPAR [38]. The I-III portion of suPAR can compete with $\mathrm{UPAR}_{\mathrm{I}-\mathrm{III}}$ for UPA binding [47]. suPAR can be found in various body fluids including blood, plasma, serum, urine, saliva, and cerebrospinal fluid (CSF) in different concentrations [22, 48, 49] and have similar functions as uPAR [38].

suPAR can be measured with a monoclonal antibody double sandwich enzyme-linked immunosorbent assay (ELISA) method using commercially available kits (e.g., R\&D Systems, Minneapolis, MN, USA; suPARnostic ${ }^{\text {TM }}$, Virogates, Copenhagen, Denmark), but only R\&D Systems were used in all the suPAR studies in FSGS. In healthy individuals, suPAR levels are stable in blood and urine and the whole molecule of suPAR was documented in serum and two truncated soluble forms of the entire molecule $\left(\operatorname{suPAR}_{\mathrm{I}}\right.$ and $\mathrm{suPAR}_{\mathrm{II}-\mathrm{III}}$ ) in the urine [50]. Elevated plasma or serum suPAR levels have been demonstrated in patients with various diseases, such as cancer, sepsis, systemic inflammatory response syndrome, and cardiovascular disease [51-55] and have been shown to be associated with a poor clinical outcome. The fact that suPAR is elevated by a large number of diseases, in particular liver and kidney diseases, makes it unlikely that suPAR can ever be used as a diagnostic biomarker (for FSGS or other diseases).

In summary, uPAR is a membrane-bound protein linked to GPI in various immunologically active cells, including podocytes, and is released as suPAR.

\section{The Role of uPAR Signaling and Integrin Activation in Podocytes and Proteinuric Kidney Diseases}

Podocyte foot processes contain an actin cytoskeleton, which is connected to the glomerular basement membrane by $\alpha 3 \beta_{1}$ and $\alpha \mathrm{v} \beta_{3}$ integrin as well as $\alpha$ and $\beta$-dystroglycans [56]. Induction of UPAR signaling in podocytes leads to foot process effacement and urinary protein loss by lipid-dependent activation of $\alpha \mathrm{v} \beta_{3}$ integrin [45]. Conversely, blocking of $\alpha \mathrm{v} \beta_{3}$ integrin also reduced podocyte motility in vitro and lowered proteinuria in mice [45]. Also, mice lacking uPAR (plasminogen activator, urokinase receptor, $P L A U R^{-/-}$) were protected from lipopolysaccharide- (LPS-) mediated proteinuria but developed disease after expression of a constitutively active $\alpha \mathrm{v} \beta_{3}$ integrin, suggesting the pathogenic role of uPAR signaling in the pathogenesis of proteinuric kidney diseases including FSGS $[9,45]$.

Recently, other groups provide further supportive evidence [57-62]. Inducible podocyte-specific expression of constitutively active nuclear factor of activated $\mathrm{T}$ cells (NFATc1) increased podocyte uPAR expression by binding to the PLAUR gene promoter [57]. Pathological uPAR signals in podocytes were independent of $\mathrm{T}$ cells and affected cell motility via activation of $\beta_{3}$ integrin. This could be blocked by cyclosporine, NFAT-siRNA, or NFAT inhibitor in animal models of glomerular diseases such as LPS-treated or 5/6 nephrectomized rats [57]. Rapamycin could promote 


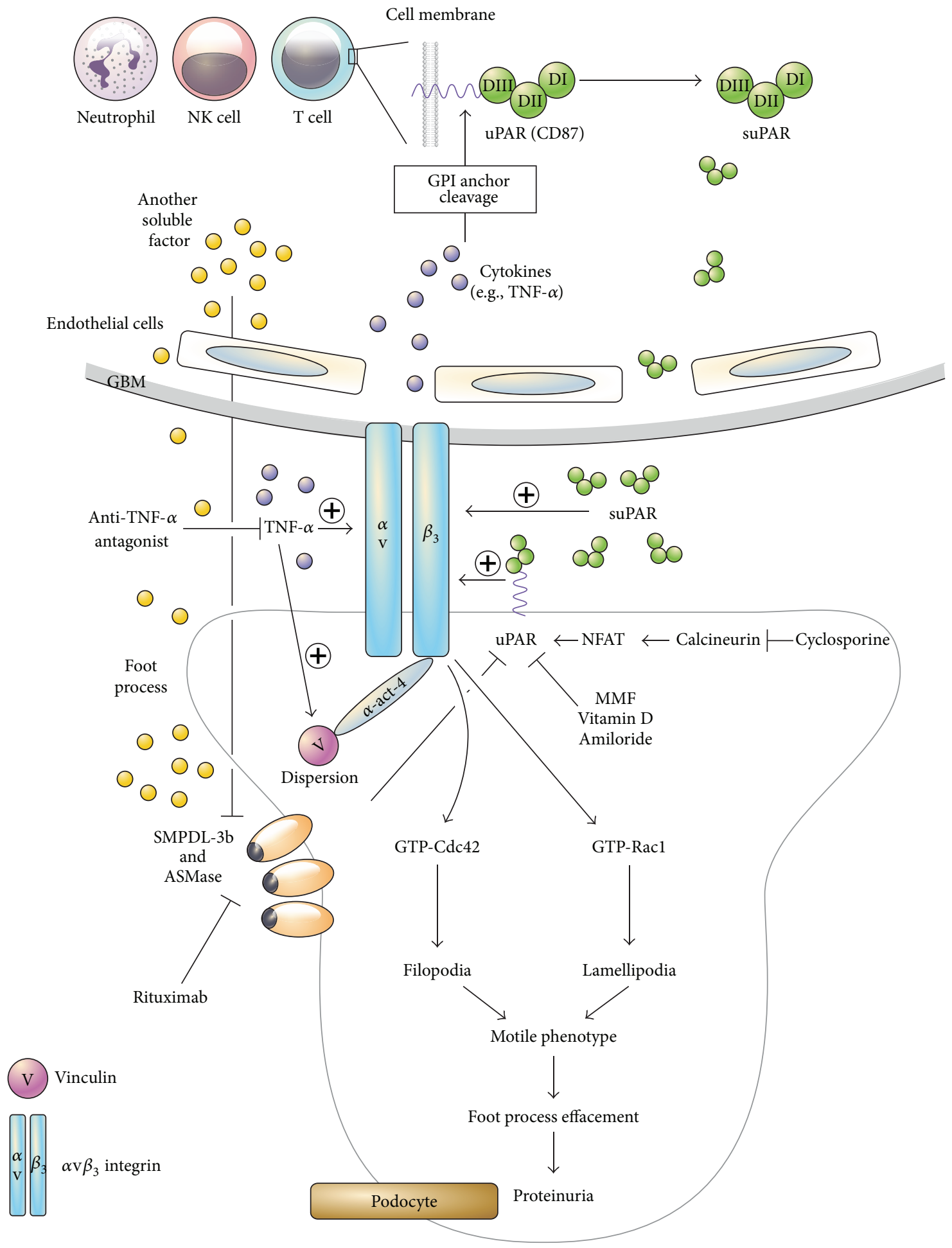

FIGURE 1: A hypothesis for the pathogenesis of suPAR-mediated FSGS. suPAR is formed from various immune cells after cleavage of GPI anchor by cytokines such as TNF- $\alpha$. suPAR can activate $\alpha \mathrm{v} \beta_{3}$ integrin of podocytes. TNF- $\alpha$ can directly activate podocyte $\alpha \mathrm{v} \beta_{3}$ integrin and vinculin. Another serum factors might decrease SMPDL3b in podocytes, causing $\alpha \mathrm{v} \beta_{3}$ integrin activation through increased binding of suPAR/uPAR and $\alpha \mathrm{v} \beta_{3}$ integrin. Cdc42 and Racl can be activated by uPAR- $\alpha \mathrm{v} \beta_{3}$ integrin signaling and the podocyte actin cytoskeleton shifts from a stationary to a motile phenotype, thereby causing foot process effacement and proteinuria. uPAR- $\alpha v \beta_{3}$ integrin signaling in podocytes can be blocked through various pathways. NK, natural killer; uPAR, urokinase-type plasminogen activator receptor; suPAR, soluble urokinase-type plasminogen activator receptor; GPI, glycosylphosphatidylinositol; TNF, tumor necrosis factor; NFAT, nuclear factor of activated T cells; MMF, mycophenolate mofetil; GTP, guanosine- $5^{\prime}$-triphosphate; SMPDL, sphingomyelin phosphodiesterase acid-like; ASMase, acid sphingomyelinase. 
podocyte migration through the upregulation of uPAR, providing a new mechanism of rapamycin-associated proteinuria [58]. Conversely, several drugs targeting podocyte uPAR expression, such as vitamin $\mathrm{D}$, amiloride, or mycophenolate mofetil (MMF), have recently been shown to be effective in reducing proteinuria in various experimental models, such as FSGS or lupus mice [59-61]. Recently, it was reported that rituximab might also inhibit uPAR- $\beta_{3}$ integrin signaling via modulation of sphingomyelin phosphodiesterase acid-like $3 \mathrm{~b}$ (SMPDL-3b) [62]. These cellular events are well summarized in Figure 1. In addition to uPAR-integrin signaling, podocyte vascular endothelial growth factor (VEGF)-A regulates $\alpha \mathrm{v} \beta_{3}$ integrin signaling in the glomerulus, and podocyte VEGF knockdown disrupts $\alpha \mathrm{v} \beta_{3}$ integrin activity [63].

In summary, uPAR- $\alpha v \beta_{3}$ integrin signaling is an important pathway in the pathogenesis of proteinuria in various kidney diseases.

\section{The Role of suPAR in Podocytes and FSGS}

Wei et al. reported that circulating suPAR could activate $\beta_{3}$ integrin in a similar manner to membrane-bound UPAR in podocytes by using the methods of coimmunoprecipitation of suPAR and $\beta_{3}$ integrin and the activating epitope-recognizing antibodies such as the $\beta_{3}$ integrin-specific antibody AP5 [9]. They found that the incubation of podocytes with recombinant suPAR strongly induces AP5 signal in a specific pattern highlighting areas of focal adhesions, which are known to be the location of $\beta_{3}$ integrin. This effect was blocked by a blocking specific uPAR antibody [9].

They established three different mouse models [9]. The first was $P L A U R^{-/-}$mice: high-dose recombinant mouse suPAR $_{\mathrm{I}-\mathrm{III}}$ induced proteinuria and foot process effacement, prominent deposits of suPAR on podocytes as well as increased podocyte $\beta_{3}$ integrin activity [9]. The second model was hybrid-transplant mice modeling endogenous suPAR release in which a kidney from $P L A U R^{-/-}$mice was transplanted in a wild-type mouse and proteinuria developed after LPS-induced suPAR production, indicating that circulating suPAR may be able to activate $\beta_{3}$ integrin independently of UPAR [9]. The third model was genetically engineered wildtype mice. Wild-type mice were injected with a suPAR $\mathrm{III}^{-}$ producing plasmid into their skin, which caused increased serum suPAR concentrations and FSGS-like lesions with proteinuria. A plasmid with a point mutation in the $\mathrm{D}_{\text {II }}$ domain induced synthesis of suPAR in wild-type mice. However, this was unable to bind to $\beta_{3}$ integrin and did not induce proteinuria [9].

In their study, serum suPAR concentrations were significantly elevated in patients with FSGS compared to those with minimal change disease $(\mathrm{MCD}$, either in relapse or remission), membranous nephropathy (MN), preeclampsia, and healthy subjects [9]. suPAR concentrations correlated with the activity of podocyte $\beta_{3}$ integrin and inhibition of suPAR by cycloRGDfV or antibodies specific against uPAR and plasmapheresis could lower AP5 activity on podocytes [9]. They also found a predominant suPAR fragment at $\sim 22 \mathrm{kDa}$ and the other two forms at $\sim 45$ and $40 \mathrm{kDa}$, albeit at much lower expression levels [9]. However, serum uPA concentrations did not differ between FSGS and other glomerular diseases [9].

In summary, Wei et al. [9] reported an important role of suPAR in the pathogenesis of FSGS with in vitro podocytes, 3 mice models of FSGS, and FSGS patients.

\section{Subsequent Clinical Observations Supporting the Pathogenic Role of SUPAR in FSGS}

In two large cohorts, circulating suPAR levels were elevated in 84.3\% (North American) and 55.3\% (the European PodoNet) of the FSGS patients compared with $6 \%$ of controls [10]. Inflammation did not account for this difference [10]. Serum suPAR levels were also increased in FSGS compared to other glomerulopathies such as MCD or MN and healthy subjects [9-13]. However, serum suPAR levels did not differ between primary and secondary FSGS [12]. One study showed that elevated suPAR levels in primary FSGS were not merely attributable to decreased estimated eGFR, because suPAR levels of primary FSGS were still significantly higher than $\mathrm{MCD}$ or MN after adjusting for renal function [12]. One study reported the usefulness of suPAR measurements in predicting steroid response in patients with primary FSGS [13].

In 2001, Kemper et al. reported an infant with transient proteinuria born to a mother with FSGS [35] and a recent reanalysis of stored samples revealed highly elevated suPAR levels in both the mother and the newborn [64]. Extracorporeal treatment reduced suPAR, podocyte $\beta_{3}$ integrin activation, podocyte effacement, and proteinuria in recurrent FSGS patients in accordance with reduction of suPAR levels [65, 66].

Recently, it was reported that urinary suPAR levels of patients with primary FSGS were significantly higher compared to those with MCD, MN, and secondary FSGS and normal subjects [67] and positively correlated with 24-hour urinary protein excretion in primary FSGS. During followup, urinary suPAR levels decreased in patients with complete remission. After incubation of human podocytes with urine obtained from patients with primary FSGS, the AP5 signal was induced and it could be reduced by a blocking antibody to uPAR [67].

\section{Clinical Observations Not Supporting the Pathogenic Role of suPAR in FSGS}

Although increased suPAR levels resulted in FSGS-like glomerular lesions and proteinuria in $P L A U R^{-/-}$mice [9], the pathogenic effects of suPAR were not observed in wild-type mice, in which proteinuria or podocyte foot process effacement did not occur despite glomerular suPAR deposition [23, 68]. suPAR concentrations did not distinguish patients with FSGS from other glomerular histopathologies such as MCD, $\mathrm{MN}$, IgA nephropathy, and lupus nephritis or nonglomerular chronic kidney disease (CKD), suggesting that suPAR might be involved in the pathogenesis of various renal diseases as a nonspecific marker or impaired glomerular integrity 
might affect its clearance [14-24]. Moreover, eGFR was the strongest determinant of suPAR concentration [14-24]. Therefore, more work is warranted and justified to explore the role of suPAR in FSGS and other glomerular diseases.

Wei et al. reported that pretransplant serum suPAR levels predicted posttransplant recurrence of FSGS [9], whereas several other investigators found no evidence that serum suPAR was a specific marker for FSGS recurrence [18, 22, 69]. Although there have been studies demonstrating a decrease of suPAR after the induction of remission $[10,12,65,66]$, others demonstrated similar serum levels regardless of therapeutic response $[15,18,70]$. Recently, it was demonstrated that urinary suPAR levels rather than serum suPAR levels might be helpful in the early identification of patients at high risk of posttransplant FSGS recurrence [22].

From an epidemiologic point of view, statistical validation is also one of the important steps to be a reliable surrogate biomarker from biomarker discovery to clinical utility [71]. A biomarker for clinical use needs good sensitivity and specificity (e.g., $\geq 0.9$ ) and good positive and negative predictive value. However, previous studies on suPAR had many problems in the study designs, sample collection, and statistical analysis techniques. Most studies on suPAR were conducted in a retrospective design and the selection of healthy controls was not matched for age, sex, and other parameters influencing suPAR levels. With regard to statistics, most studies did not perform multiple logistic regression analysis to find an independent predictor and receiver operating characteristics (ROC) curve analysis to calculate sensitivity and specificity, an essential prerequisite to be a biomarker, but simply presented the differences of suPAR levels among groups. Furthermore, some studies did not present the mean \pm standard deviation (SD), hampering the meta-analysis of several suPAR studies. If there are many factors influencing suPAR levels, an individual patient data meta-analysis and propensity score matching would be important statistical methods to elucidate whether suPAR could be a reliable surrogate biomarker in this field.

There has also been interest in reproducibility concerns in medicine [72]. In addition to registration of the study design (i.e., http://www.clinicaltrials.gov/), the adoption and following of the guidelines such as STrengthening the Reporting of OBservational studies in Epidemiology (STROBE) for cohort and case control studies would increase the reproducibility and reliability in human studies [73]. Irreproducibility of preclinical animal data can also lead to the failure of human clinical trials and ARRIVE (Animal Research: Reporting of In Vivo Experiments) for animal studies which may improve the quality of animal research and increase transparency and reproducibility [74].

\section{Areas of Uncertainty concerning Preclinical Studies Investigating SuPAR in FSGS}

8.1. Different Mice Models Used in suPAR Studies. The search for a good model of human recurrent FSGS is indeed a key to future studies and has yet to be developed. In our opinion, the most appropriate mouse model to study FSGS-like lesions should be determined. The animal models described are specific to studies of suPAR and may not be useful if other factors or cofactors are responsible for this disease. While Wei et al. used $P L A U R^{-/-}$mice and genetically engineered wildtype mice with injection of a suPAR $\mathrm{I}_{\mathrm{II}}$-producing plasmid, most others performed studies with wild-type mice [9]. Maas et al. pointed out that wild-type nonproteinuric mice used in the original study already exhibited suPAR levels of approximately $3,000 \mathrm{pg} / \mathrm{mL}$ at baseline before activation of the plasmid [75]. After initiation of recombinant suPAR expression, mice developed proteinuria along with a sharp rise in urinary suPAR excretion and rise of serum suPAR. However, these mice with high baseline suPAR might be prone to develop FSGS [9]. In contrast, Cathelin et al. used wild-type C57BL/6J and 129S2/SvPas mice and intravenous administration of suPAR could not cause proteinuria despite massive suPAR deposits in the glomeruli in these mice and did not aggravate proteinuria in LPS-treated C57BL/6J mice [68]. They addressed that if the genetic ablation of PLAUR in the kidney is the cause of the effect observed on proteinuria, it is difficult to translate this finding to the pathogenesis of FSGS in humans. They also pointed out that the plasmid used in genetically engineered WT mice by Wei et al. [9] encodes a truncated mRNA splice variant of mouse uPAR covering the first 133 residues of the full-length receptor and this particular splice mRNA transcript may not be translated into a folded protein product in vivo because it encodes only one and one half LU-domain [68].

Spinale et al. also used wild-type and a transgenic mouse model continuously inducing hepatic suPAR expression (D1D2D3) in which proteinuria did not develop despite an increase of suPAR [23]. They pointed out that Wei et al. [9] injected a commercially available mouse recombinant Fc-fusion protein in short-term experiments that coupled a human IgG1 Fc-domain to mouse uPAR lacking a GPIlinkage motif and it has not been determined whether IgG1 Fc domain containing protein engendered complement fixationdependent glomerular injury [23]. They also addressed that Wei et al. [9] used a mouse suPAR cDNA fragment obtained from a purchased cDNA clone (IMAGE cDNA clone 3158012) containing a retained intron 4 (uPAR-intron 4) and the mouse splice variant encoding uPAR-intron 4 is rare and the expression of the protein associated with this variant has not been reported [23]. In addition, they indicated that Wei et al. [9] reported the creation of a control mouse suPAR construct with an E134A mutation intended to abrogate binding of mouse suPAR to $\beta_{3}$ integrin, but a similar $\beta_{3}$ integrin binding motif has not been described in mouse uPAR [23].

In various inflammatory conditions, an increase in serum suPAR levels has been reported which was not associated with proteinuria $[38,48,53,54,76]$, suggesting that suPAR itself may not be sufficient to induce nephrotic proteinuria as in wild-type mice.

In our opinion, however, the threshold of serum suPAR at which proteinuria and a FSGS-like lesion develop should be determined both in wild-type mice $[23,68]$ and in $P L A U R^{-/-}$ mice [9], requiring further dose-response experiments in different animal models of FSGS in the future. We speculate that much higher doses and more prolonged administration 
of suPAR could be used to determine the threshold in wildtype mice. In addition, with regard to the measurements of suPAR levels in mice, Cathelin et al. did not measure serum suPAR levels in suPAR-treated mice [68]. Wei et al. described that murine suPAR was evaluated by an in-house ELISA kit [9] and Spinale et al. reported that suPAR concentration in mouse serum was measured with a kit from R\&D Systems (Minneapolis, MN) (DY531) which has been validated by the manufacturer for detection of mouse suPAR in cell supernatant [23]. The measurements of suPAR levels by ELISA methods in mice should be unified and further validated in both wild-type and genetically engineered mice in future studies for the comparison.

In summary, we cannot say that suPAR is not involved in the pathogenesis of FSGS in mice, because different experimental models were used.

8.2. In Vitro suPAR Studies on Podocytes. Wei et al. demonstrated that recombinant suPAR activates $\beta_{3}$ integrin (AP5 staining) in a similar manner to membrane-bound UPAR in podocytes, which was blocked by an antibody specific to uPAR. Currently, however, no further study has repeated and validated these findings [9]. Therefore, factors mediating suPAR-induced activation of $\alpha \mathrm{v} \beta_{3}$ integrin need to be elucidated. Jefferson and Alpers speculated that activation of $\alpha v \beta_{3}$ signaling by suPAR might require additional modifying factors such as loss of podocyte protective factors or an underlying permissive genetic background [77].

Recently, Yoo et al. [78] reported that SMPDL-3b is an important regulator of suPAR-induced activation of $\alpha \mathrm{v} \beta_{3}$ integrin signaling in podocytes. SMPDL-3b interferes with binding of suPAR/uPAR and $\alpha \mathrm{v} \beta_{3}$ integrin, attenuating $\alpha \mathrm{v} \beta_{3}$ integrin activation. They showed that SMPDL-3b expression is decreased in glomeruli of patients with recurrent FSGS and FSGS sera-treated podocytes exhibited decreased SMPDL-3b expression [78]. Therefore, high suPAR levels could increase podocytic $\alpha \mathrm{v} \beta_{3}$ integrin activation in FSGS patients with nephrotic syndrome, while intact SMPDL-3b expression in podocytes of normal subjects might offset $\alpha \mathrm{v} \beta_{3}$ integrin activation by inflammation-driven high suPAR. Notably, they demonstrated that high suPAR in the presence of increased podocyte SMPDL-3b levels in diabetic nephropathy did not activate $\alpha \mathrm{v} \beta_{3}$ integrin but led to RhoA activation and podocyte apoptosis, indicating different effector pathways in suPAR signaling [78].

We should also note that FSGS sera-treated podocytes exhibited decreased SMPDL-3b expression but suPAR itself did not modulate SMPDL-3b expression levels [78]. Therefore, in our opinion, other unknown factors in FSGS might reduce the SMPDL-3b expression in injured podocytes, increasing the effect of suPAR on podocytes, and this has to be clarified (Figure 1).

In summary, the role of suPAR in activating $\beta_{3}$ integrin in podocytes has not been repeated in other groups and further validation is necessary.

\section{Areas of Uncertainty concerning the Sources of SUPAR}

As mentioned above, various suPAR fragments exist with different characteristics and whether or not the "true" circulatory factor is a cleaved suPAR isoform remains obscure. Wei et al. found a predominant suPAR fragment at $\sim 22 \mathrm{kDa}[9]$. The importance of different suPAR domains was highlighted by the finding that suPAR administration in mice producing suPAR $\mathrm{D}_{\mathrm{I}}$ and $\mathrm{D}_{\mathrm{II}}$ domains induced albuminuria [9]. Trachtman et al. considered that it is likely that all forms of suPAR can bind to $\alpha \mathrm{v} \beta_{3}$ integrin, but subsequent activation might vary depending on the specific form of suPAR [79]. Maas et al. speculated that vitronectin-binding capacity of suPAR fragments might determine the activity as a FSGS factor [75]. In addition, it should be considered that a glycosylation status of suPAR may be causative of inducing proteinuria in primary FSGS [80]. Because the currently available ELISA kits can detect full-length glycosylated suPAR only [80], characterization of the different isoforms and their biologic activity is clearly warranted and should be addressed by further studies, using novel kits. In addition, the levels of different isoforms in active FSGS should be clearly clarified, as the original clinical studies are difficult to reconcile if it is only a specific isoform that is biologically active.

In summary, isoforms and glycosylation status of suPAR should be considered and detection kits should be developed in the future.

\section{Areas of Uncertainty concerning SuPAR Serum Determinants}

The time of specimen collection may influence suPAR levels [81]. However, no differences between serum and plasma suPAR levels were observed when samples were kept at room temperature for a few hours, but suPAR levels increased after an observation time of 72 hours. Repeated freeze and thaw cycles had no influence on suPAR levels [82]. Therefore, uniform specimen collection and only short-term storage at room temperature should be targeted.

The relevance of demographics in the interpretation of serum suPAR has to be highlighted. In healthy adults, mean suPAR concentrations of approximately 2,000-4,000 pg/mL have been reported [52]. Although there have only been few studies on potential factors influencing suPAR levels in the normal population, higher suPAR levels were found in women, smokers, older subjects, and Africans (compared to Caucasians) $[52,83]$. Therefore, there is a strong need to include these confounding factors in future studies investigating the role of suPAR in FSGS.

Markers of systemic inflammation (i.e., C-reactive protein (CRP) or erythrocyte sedimentation rate (ESR)) should be determined as well, since inflammation per se can affect suPAR levels $[16,18,52,76]$. A positive correlation between suPAR and either CRP or ESR levels was shown in patients with rheumatoid arthritis [76]. No correlation has been reported between CRP and suPAR levels in FSGS so far [10, 13, 17]. However, there were correlations between suPAR and high sensitivity CRP (hsCRP) levels or log CRP $[16,18]$. There remains uncertainty towards the value of CRP as inflammatory marker in nephrotic disease, but the use of hsCRP may be a more appropriate measure to correlate with suPAR [18] and might be used in further studies. 
In most studies, eGFR is one of the strongest determinants of suPAR concentration [14-24], but these findings could not be confirmed in two studies $[9,13]$. Accumulation of suPAR in patients at low GFR may obfuscate FSGS-induced suPAR accumulation [84]. Information about clearance, production, and release of suPAR in patients with preserved or impaired kidney function is lacking. Although several factors such as inflammatory cytokines are increased in chronic kidney disease (CKD) [85-87], we still do not know whether these changes may lead to increased suPAR levels or not. In one study, hemodialysis patients had very high suPAR levels. The median suPAR in these patients was $12.3 \mathrm{ng} / \mathrm{mL}$ (controls $3.2 \mathrm{ng} / \mathrm{mL}$, suPARnostic assay), which makes this group of patients quite unique with regard to the extremely high suPAR level [88].

In summary, suPAR serum determinants (collection time of blood, ethnic differences, systemic inflammation, eGFR, and metabolism of suPAR) should be considered in interpreting the results.

\section{Areas of Uncertainty concerning SUPAR in FSGS}

Most studies did not correlate suPAR levels with the different histopathological variants of primary FSGS. Others reported no differences among FSGS subtypes [11, 13, 89]. However, Huang et al. found that suPAR levels were higher in tip-lesion FSGS, followed by not otherwise specified and cellular variant [12], whereas urinary suPAR levels were highest in patients with the cellular variant [67]. They found no differences in suPAR levels between primary and secondary FSGS [12], but Segarra et al. found an association of suPAR levels with the diagnosis of primary FSGS after adjusting for age, renal function, and presence of nephrotic syndrome [89]. We propose that multiple cohorts should be reanalyzed according to the Columbia classification of primary FSGS to highlight potential differences between the variants and this should be considered in future studies as well.

Circulating factors such as suPAR have their most significant role in patients at risk of recurrent FSGS after KT. However, most studies did not measure suPAR levels in recurrent versus nonrecurrent FSGS [11-24]. Another limitation of research may be misclassification of FSGS cases, since distinction between primary and secondary FSGS may not be feasible in all patients. Wei et al. reported that FSGS patients with an NPHS2 mutation had higher suPAR levels than those without [10], but Maas et al. questioned this result, because it is in contrast with the observation that recurrences of FSGS occur most frequently in patients with nongenetic, primary FSGS [75]. Jungraithmayr et al. reported that none of the 11 patients with homozygous or compound heterozygous NPHS2 mutations developed recurrent FSGS after KT compared with $45 \%$ of patients without mutations [90]. Therefore, higher suPAR levels in FSGS patients with an NPHS2 mutation might not influence the risk of recurrence after KT. The incidence of NPHS2 mutations seems to be very rare in Asian countries [91] and therefore suPAR studies from Asian countries might rarely include FSGS patients with podocin mutations. Early studies suggested that a few patients with NPHS2 "mutations" do develop FSGS recurrence after KT $[92,93]$, but subsequent information suggests that these may not be true disease causing variants.

In summary, the role of suPAR should be interpreted in the context with recurrent FSGS after KT, which is considered to be circulating factor-mediated.

\section{Areas of Uncertainty concerning Immunosuppression and suPAR Levels}

The use of immunosuppressive drugs (the kinds, the cumulative dose, and the duration of immunosuppressants) at the time of suPAR measurements should be considered. Although most studies did not describe this crucial parameter, suPAR in the European PodoNet cohort comprising steroid-resistant children and adolescents revealed lower levels in the MMF-treated group, while no difference was observed in patients with or without calcineurin inhibitor treatment [10]. Wada et al. showed that suPAR levels were significantly lower in FSGS patients with normal renal function who were treated with steroids or immunosuppressants than in those without, but the use of steroids/immunosuppressants was not predictive of suPAR levels in those with glomerular diseases [17]. Sinha et al. reported that serum suPAR levels did not correlate with the duration of immunosuppressive therapy [18]. A recent study showed that serum suPAR levels decreased after MMF therapy, while they increased after cyclosporine treatment in children with MCD and frequently relapsing steroid-sensitive nephrotic syndrome with normal renal function, suggesting that immunosuppressants per se might have diverse effects on suPAR levels [94].

The immunologic nature of suPAR has to be considered, because it may be influenced secondarily by immune activation. There might be an influence of cytokines such as TNF- $\alpha$ and interleukin-2 (IL-2) on suPAR [95-97]. Although not tested in FSGS, suPAR correlated with leukocyte count and TNF- $\alpha$ [95] and several suPAR isoforms with soluble TNF receptor-II in HIV-infected patients [96]. TNF- $\alpha$ was supposed to be critical for uPAR expression on platelets [98]. Park et al. recently speculated that IL- 2 might be an important cytokine for the formation of suPAR from $\mathrm{T}$ cells and natural killer cells in FSGS [97].

Recently, Delville et al. [99] screened about 9000 antigens in pretransplant sera of FSGS and pretransplant elevation of anti-CD40 antibody (Ab) alone had the best correlation (78\% accuracy) with recurrent FSGS risk after KT among seven Abs (CD40, PTPRO, CGB5, FAS, P2RY11, SNRPB2, and APOL2). Anti-CD40 Abs purified from the sera of recurrent FSGS patients were particularly pathogenic in human podocyte cultures and injection of anti-CD40/rFSGS Ab enhanced suPAR-mediated proteinuria in wild-type mice, but no sensitizing effect was noted in mice deficient in CD40 or in wildtype mice that received blocking $\mathrm{Ab}$ to $\mathrm{CD} 40$, supporting the fact that suPAR might be formed by immunologically mediated mechanisms in FSGS [99]. Therefore, further investigations are necessary to elucidate the role of various immunological molecules on podocytes, mice models of FSGS, and patients with FSGS. 
More recently, recurrent FSGS after KT was successfully treated with immunosuppressive treatments with high-dose methylprednisolone and cyclosporine [100], potentially suppressing TNF- $\alpha$ and IL-2. A TNF- $\alpha$ driven pathway in primary FSGS has also been supported by findings of Bitzan et al. who reported a patient with recurrent and plasmapheresisresistant FSGS with sustained partial remission of proteinuria after initiation of anti-TNF- $\alpha$ therapy despite discontinuation of plasmapheresis [101]. Moreover, they showed that activated podocyte $\beta_{3}$ integrin by plasma from patients with FSGS recurrence could be reversed by blocking TNF- $\alpha$ in vitro (Figure 1) [101].

Therefore, in our opinion, increased circulating factors such as suPAR might reflect a secondary effect of immune activation in FSGS. Treatment suppressing cytokines such as TNF- $\alpha$ and IL- 2 could induce remission possibly due to a decrease of the circulating factors. It was speculated that a cytokine such as TNF- $\alpha$ might have direct deleterious effects on podocytes in vivo [102] and this effect could be therapeutically targeted. However, the question remains whether TNF- $\alpha$ is the specific elusive "factor" or just one out of several factors affecting the glomerular filtration barrier or modulating the immune response [102]. We think that glomerular diseases like FSGS may develop when suPAR interacts with other factors that injure podocytes in a proposed multiple hit process. However, the precise effects of TNF- $\alpha$ or IL-2 on podocytes have not been elucidated leaving the opportunity that an inflammatory signal rather than suPAR is causing FSGS-type lesions. We encourage consideration of additive or synergic effects of several influences (circulatory factors, genetic susceptibility, and local immunologic changes) on the glomerular filtration barrier of which suPAR may be one such influence or may be pathologically altered by other cytokines.

In summary, suPAR may be an immunologically mediated molecule and immunosuppression can suppress the suPAR levels.

\section{Conclusions and Future Perspectives}

Circulating factors have been implicated in the pathogenesis of recurrent FSGS after KT $[7,8]$ and suPAR has been suggested as a potential candidate. Circulating suPAR could activate $\beta_{3}$ integrin in a similar manner to membrane-bound uPAR in podocytes, but further validations are necessary to elucidate how much activation of $\beta_{3}$ integrin is relevant to cause foot process effacement. suPAR could induce proteinuria in vulnerable mice models [9], but administration of suPAR to wild-type mice did not induce proteinuria $[23,68]$. There might be a pivotal role of additional hits, such as increased TNF- $\alpha$ and IL-2 or decreased SMPDL-3b expression in podocytes in the development of proteinuria [78, 97, 101]. In the clinical setting, recurrent nephrotic range proteinuria in patients with nongenetic disease can be abrogated by intensive immunosuppression possibly due to repression of circulating factor formation, stabilization of the actin cytoskeleton (e.g., cyclosporine), or prevention of SMPDL-3b downregulation (e.g., rituximab) [62, 100, 103-106].
The conflicting results on suPAR levels between FSGS and other glomerular diseases or controls may be attributable to the heterogeneous nature of FSGS and various confounding factors as stated above. As stated above, clinical studies should be designed taking into account important covariates, for example, the GFR. Future studies should also be designed to formally evaluate the sensitivity, specificity, and predictive value of suPAR.

We summarized the different results on various suPAR studies in FSGS in Tables 1 and 2 and showed an integrative model for the pathogenesis of circulating factor-mediated FSGS in Figure 1. In our opinion, the data on the nature and biological effect of specific suPAR molecular fragments are incomplete so far. A single suPAR value is of no use as clinical biomarker and suPAR itself may not be sufficient to induce FSGS lesions. However, the downstream biological effects via $\alpha v \beta_{3}$ integrin may still be valid and suPAR might activate $\alpha v \beta_{3}$ integrin under other coexisting conditions such as reduced SMPDL-3b expression by other serum factors of FSGS or a costimulatory effect with TNF- $\alpha$.

We recommend and encourage further investigations in this field to elucidate the role of various immunological molecules on podocytes, mice models of FSGS, and patients with FSGS. We suggest multicenter collaborative studies to clarify the controversies related to suPAR as circulatory factor in FSGS. We believe that understanding the immunology in this field may facilitate unraveling pathogenic mechanisms leading to FSGS.

\section{Competing Interests}

Andreas Kronbichler has been supported by the ERA-EDTA with a long-term fellowship (12 months) from August 2014 to August 2015 and has received research grants from Roche/ Genentech and GlaxoSmithKline. Björn Meijers received support from the Research Foundation-Flanders (FWO) (Grant G077514N) and has received research support from Bellco and Gambro/Baxter.

\section{Authors' Contributions}

Andreas Kronbichler, Moin A. Saleem, Björn Meijers, and Jae Il Shin contributed to conception and design of the study. Andreas Kronbichler, Moin A. Saleem, Björn Meijers, and Jae Il Shin carried out analysis of the data. All authors drafted the paper or revised it critically for important intellectual content. All authors approved the final version of the paper to be published.

\section{Acknowledgments}

The authors would like to thank Professor Jun Oh (Division of Nephrology, Department of Pediatrics, University Hospital Hamburg-Eppendorf, Hamburg, Germany) for his helpful comments. They would also like to express their gratitude to Dong Soo Jang, Ji Hye Kim, Hwa Jeong You, and Dong Yeon Jeong for the illustration of the figure. 


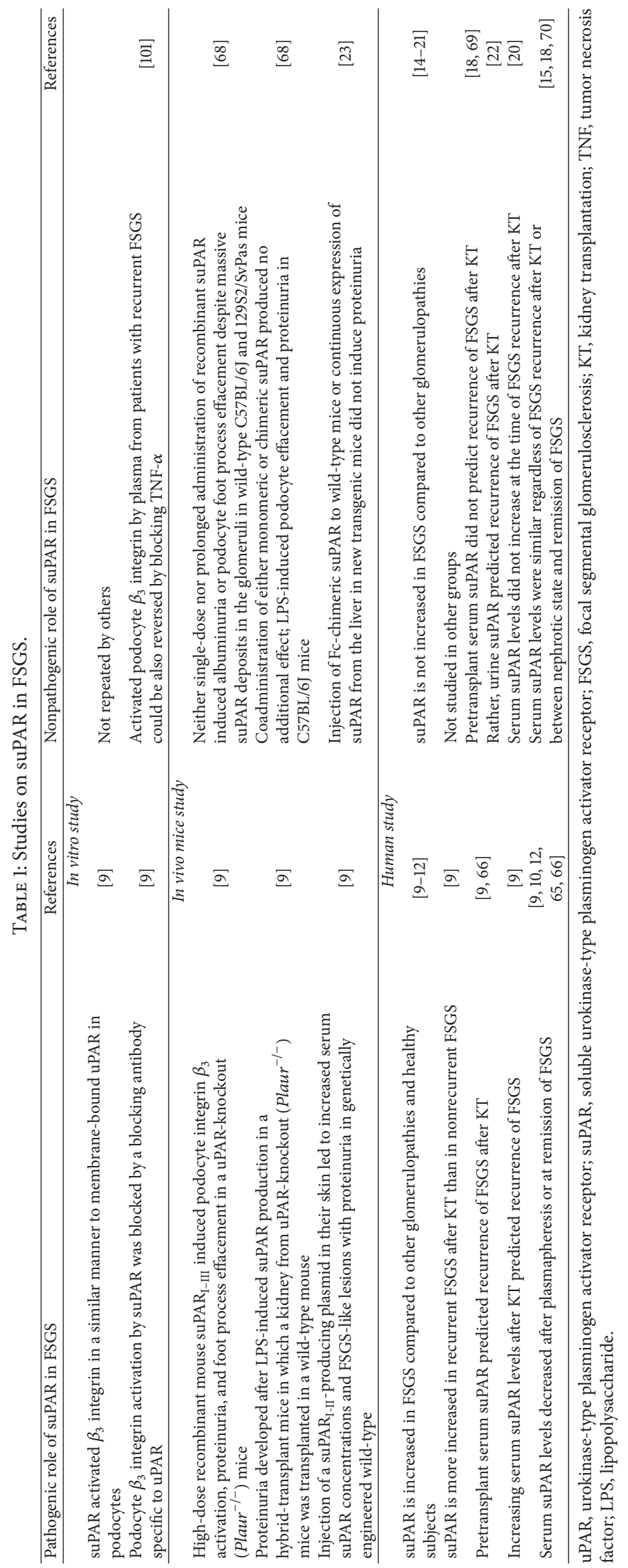




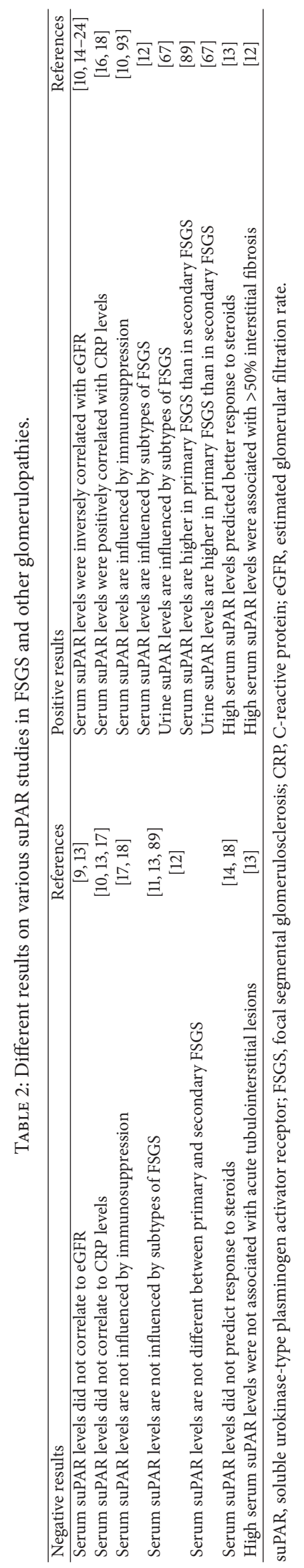




\section{References}

[1] A. B. Fogo, "Causes and pathogenesis of focal segmental glomerulosclerosis," Nature Reviews Nephrology, vol. 11, no. 2, pp. 7687, 2015.

[2] B. Bose and D. Cattran, "Glomerular diseases: FSGS," Clinical Journal of the American Society of Nephrology, vol. 9, no. 3, pp. 626-632, 2014.

[3] W. Y. Ding, A. Koziell, H. J. McCarthy et al., "Initial steroid sensitivity in children with steroid-resistant nephrotic syndrome predicts post-transplant recurrence," Journal of the American Society of Nephrology, vol. 25, no. 6, pp. 1342-1348, 2014.

[4] J. A. Jefferson and S. J. Shankland, "The pathogenesis of focal segmental glomerulosclerosis," Advances in Chronic Kidney Disease, vol. 21, no. 5, pp. 408-416, 2014.

[5] S. M. L. de Mik, M. J. Hoogduijn, R. W. de Bruin, and F. J. M. F. Dor, "Pathophysiology and treatment of focal segmental glomerulosclerosis: the role of animal models," BMC Nephrology, vol. 14, article 74, 2013.

[6] C. Schell and T. B. Huber, "New players in the pathogenesis of focal segmental glomerulosclerosis," Nephrology Dialysis Transplantation, vol. 27, no. 9, pp. 3406-3412, 2012.

[7] E. T. McCarthy, M. Sharma, and V. J. Savin, "Circulating permeability factors in idiopathic nephrotic syndrome and focal segmental glomerulosclerosis," Clinical Journal of the American Society of Nephrology, vol. 5, no. 11, pp. 2115-2121, 2010.

[8] J. Reiser, C. C. Nast, and N. Alachkar, "Permeability factors in focal and segmental glomerulosclerosis," Advances in Chronic Kidney Disease, vol. 21, no. 5, pp. 417-421, 2014.

[9] C. Wei, S. El Hindi, J. Li et al., "Circulating urokinase receptor as a cause of focal segmental glomerulosclerosis," Nature Medicine, vol. 17, no. 8, pp. 952-960, 2011.

[10] C. Wei, H. Trachtman, J. Li et al., "Circulating suPAR in two cohorts of primary FSGS," Journal of the American Society of Nephrology, vol. 23, no. 12, pp. 2051-2059, 2012.

[11] G. Cara-Fuentes, C. Wei, A. Segarra et al., "CD80 and suPAR in patients with minimal change disease and focal segmental glomerulosclerosis: diagnostic and pathogenic significance," Pediatric Nephrology, vol. 29, no. 8, pp. 1363-1371, 2014.

[12] J. Huang, G. Liu, Y.-M. Zhang et al., "Plasma soluble urokinase receptor levels are increased but do not distinguish primary from secondary focal segmental glomerulosclerosis," Kidney International, vol. 84, no. 2, pp. 366-372, 2013.

[13] F. Li, C. Zheng, Y. Zhong et al., "Relationship between serum soluble urokinase plasminogen activator receptor level and steroid responsiveness in FSGS," Clinical Journal of the American Society of Nephrology, vol. 9, no. 11, pp. 1903-1911, 2014.

[14] R. J. H. Maas, J. F. M. Wetzels, and J. K. J. Deegens, "Serumsoluble urokinase receptor concentration in primary FSGS," Kidney International, vol. 81, no. 10, pp. 1043-1044, 2012.

[15] M. E. Bock, H. E. Price, L. Gallon, and C. B. Langman, "Serum soluble urokinase-type plasminogen activator receptor levels and idiopathic FSGS in children: a single-center report," Clinical Journal of the American Society of Nephrology, vol. 8, no. 8, pp. 1304-1311, 2013.

[16] B. Meijers, R. J. H. Maas, B. Sprangers et al., “The soluble urokinase receptor is not a clinical marker for focal segmental glomerulosclerosis," Kidney International, vol. 85, no. 3, pp. 636-640, 2014.

[17] T. Wada, M. Nangaku, S. Maruyama et al., "A multicenter cross-sectional study of circulating soluble urokinase receptor in Japanese patients with glomerular disease," Kidney International, vol. 85, no. 3, pp. 641-648, 2014.

[18] A. Sinha, J. Bajpai, S. Saini et al., "Serum-soluble urokinase receptor levels do not distinguish focal segmental glomerulosclerosis from other causes of nephrotic syndrome in children," Kidney International, vol. 85, no. 3, pp. 649-658, 2014.

[19] A. Segarra, E. Jatem, M. T. Quiles et al., "Diagnostic value of soluble urokinase receptor serum levels in adults with idiopathic nephrotic syndrome," Nefrologia, vol. 34, no. 1, pp. 46-52, 2014.

[20] Y. Harita, K. Ishizuka, A. Tanego et al., "Decreased glomerular filtration as the primary factor of elevated circulating suPAR levels in focal segmental glomerulosclerosis," Pediatric Nephrology, vol. 29, no. 9, pp. 1553-1560, 2014.

[21] C. Musetti, M. Quaglia, T. Cena et al., "Circulating suPAR levels are affected by glomerular filtration rate and proteinuria in primary and secondary glomerulonephritis," Journal of Nephrology, vol. 28, no. 3, pp. 299-305, 2015.

[22] C. R. Franco Palacios, J. C. Lieske, H. M. Wadei et al., "Urine but not serum soluble urokinase receptor (suPAR) may identify cases of recurrent FSGS in kidney transplant candidates," Transplantation, vol. 96, no. 4, pp. 394-399, 2013.

[23] J. M. Spinale, L. H. Mariani, S. Kapoor et al., "A reassessment of soluble urokinase-type plasminogen activator receptor in glomerular disease," Kidney International, vol. 87, no. 3, pp. 564-574, 2015.

[24] Y. Taniguchi, Y. Shimamura, T. Horino, S. Fujimoto, and Y. Terada, "Serum levels of soluble urokinase plasminogen activator receptor in Japanese patients with chronic kidney disease," Kidney International, vol. 86, no. 1, pp. 209-210, 2014.

[25] J. R. Hoyer, L. Raij, R. Vernier, R. Simmons, J. Najarian, and A. Michael, "Recurrence of idiopathic nephrotic syndrome after renal transplantation," The Lancet, vol. 300, no. 7773, pp. 343348, 1972.

[26] M. Vinai, P. Waber, and M. G. Seikaly, "Recurrence of focal segmental glomerulosclerosis in renal allograft: an in-depth review," Pediatric Transplantation, vol. 14, no. 3, pp. 314-325, 2010.

[27] R. J. H. Maas, J. K. J. Deegens, J. A. J. G. van den Brand, E. A. M. Cornelissen, and J. F. M. Wetzels, "A retrospective study of focal segmental glomerulosclerosis: clinical criteria can identify patients at high risk for recurrent disease after first renal transplantation," BMC Nephrology, vol. 14, article 47, 2013.

[28] R. Y. Gohh, A. F. Yango, P. E. Morrissey et al., "Preemptive plasmapheresis and recurrence of FSGS in high-risk renal transplant recipients," American Journal of Transplantation, vol. 5, no. 12, pp. 2907-2912, 2005.

[29] V. J. Savin, R. Sharma, M. Sharma et al., "Circulating factor associated with increased glomerular permeability to albumin in recurrent focal segmental glomerulosclerosis," The New England Journal of Medicine, vol. 334, no. 14, pp. 878-883, 1996.

[30] M. Sharma, R. Sharma, E. T. Mccarthy, and V. J. Savin, “The FSGS factor:' enrichment and in vivo effect of activity from focal segmental glomerulosclerosis plasma," Journal of the American Society of Nephrology, vol. 10, no. 3, pp. 552-561, 1999.

[31] G. Candiano, L. Musante, M. Carraro et al., "Apolipoproteins prevent glomerular albumin permeability induced in vitro by serum from patients with focal segmental glomerulosclerosis," Journal of the American Society of Nephrology, vol. 12, no. 1, pp. 143-150, 2001.

[32] R. Sharma, M. Sharma, E. T. McCarthy, X.-L. Ge, and V. J. Savin, "Components of normal serum block the focal segmental 
glomerulosclerosis factor activity in vitro," Kidney International, vol. 58, no. 5, pp. 1973-1979, 2000.

[33] V. J. Savin, E. T. McCarthy, R. Sharma, D. Charba, and M. Sharma, "Galactose binds to focal segmental glomerulosclerosis permeability factor and inhibits its activity," Translational Research, vol. 151, no. 6, pp. 288-292, 2008.

[34] K. Sgambat, M. Banks, and A. Moudgil, "Effect of galactose on glomerular permeability and proteinuria in steroid-resistant nephrotic syndrome," Pediatric Nephrology, vol. 28, no. 11, pp. 2131-2135, 2013.

[35] M. J. Kemper, G. Wolf, and D. E. Müller-Wiefel, "Transmission of glomerular permeability factor from a mother to her child," The New England Journal of Medicine, vol. 344, no. 5, pp. 386$387,2001$.

[36] J. J. Harris, H. J. McCarthy, L. Ni et al., "Active proteases in nephrotic plasma lead to a podocin-dependent phosphorylation of VASP in podocytes via protease activated receptor-1," Journal of Pathology, vol. 229, no. 5, pp. 660-671, 2013.

[37] D. S. Charba, R. C. Wiggins, M. Goyal et al., "Antibodies to protein tyrosine phosphatase receptor type O (PTPro) increase glomerular albumin permeability (Palb)," American Journal of Physiology-Renal Physiology, vol. 297, no. 1, pp. F138-F144, 2009.

[38] M. Thunø, B. MacHo, and J. Eugen-Olsen, "suPAR: the molecular crystal ball," Disease Markers, vol. 27, no. 3-4, pp. 157-172, 2009.

[39] A. L. Roldan, M. V. Cubellis, M. T. Masucci et al., "Cloning and expression of the receptor for human urokinase plasminogen activator, a central molecule in cell surface, plasmin dependent proteolysis," The EMBO Journal, vol. 9, no. 2, pp. 467-474, 1990.

[40] T. Plesner, N. Behrendt, and M. Ploug, "Structure, function and expression on blood and bone marrow cells of the urokinasetype plasminogen activator receptor, uPAR," Stem Cells, vol. 15, no. 6, pp. 398-408, 1997.

[41] G. Al-Atrash, S. Shetty, S. Idell et al., "IL-2-mediated upregulation of uPA and uPAR in natural killer cells," Biochemical and Biophysical Research Communications, vol. 292, no. 1, pp. 184189, 2002.

[42] A. Nykjær, B. Møller, R. F. Todd III et al., "Urokinase receptor: an activation antigen in human T lymphocytes," Journal of Immunology, vol. 152, no. 2, pp. 505-516, 1994.

[43] T. Chavakis, A. K. Willuweit, F. Lupu, K. T. Preissner, and S. M. Kanse, "Release of soluble urokinase receptor from vascular cells," Thrombosis and Haemostasis, vol. 86, no. 2, pp. 689-693, 2001.

[44] H. W. Smith and C. J. Marshall, "Regulation of cell signalling by uPAR," Nature Reviews Molecular Cell Biology, vol. 11, no. 1, pp. 23-36, 2010.

[45] C. Wei, C. C. Möller, M. M. Altintas et al., "Modification of kidney barrier function by the urokinase receptor," Nature Medicine, vol. 14, no. 1, pp. 55-63, 2008.

[46] M. Ploug, E. Rønne, N. Behrendt, A. L. Jensen, F. Blasi, and K. Danø, "Cellular receptor for urokinase plasminogen activator: carboxyl-terminal processing and membrane anchoring by glycosyl-phosphatidylinositol," The Journal of Biological Chemistry, vol. 266, no. 3, pp. 1926-1933, 1991.

[47] N. Behrendt, M. Ploug, L. Patthy, G. Houen, F. Blasi, and K. Danø, "The ligand-binding domain of the cell surface receptor for urokinase-type plasminogen activator," The Journal of Biological Chemistry, vol. 266, no. 12, pp. 7842-7847, 1991.
[48] C. Østergaard, T. Benfield, J. D. Lundgren, and J. Eugen-Olsen, "Soluble urokinase receptor is elevated in cerebrospinal fluid from patients with purulent meningitis and is associated with fatal outcome," Scandinavian Journal of Infectious Diseases, vol. 36, no. 1, pp. 14-19, 2004.

[49] A. Gustafsson, V. Ajeti, and L. Ljunggren, "Detection of suPAR in the saliva of healthy young adults: comparison with plasma levels," Biomarker Insights, vol. 6, pp. 119-125, 2011.

[50] N. Sidenius, C. F. M. Sier, and F. Blasi, "Shedding and cleavage of the urokinase receptor (uPAR): identification and characterisation of uPAR fragments in vitro and in vivo," FEBS Letters, vol. 475, no. 1, pp. 52-56, 2000.

[51] J. Eugen-Olsen, O. Andersen, A. Linneberg et al., "Circulating soluble urokinase plasminogen activator receptor predicts cancer, cardiovascular disease, diabetes and mortality in the general population," Journal of Internal Medicine, vol. 268, no. 3, pp. 296-308, 2010.

[52] M. Persson, G. Engström, H. Björkbacka, and B. Hedblad, "Soluble urokinase plasminogen activator receptor in plasma is associated with incidence of CVD. Results from the Malmö Diet and Cancer Study," Atherosclerosis, vol. 220, no. 2, pp. 502-505, 2012.

[53] K. Donadello, S. Scolletta, C. Covajes, and J.-L. Vincent, "suPAR as a prognostic biomarker in sepsis," BMC Medicine, vol. 10, article 2, 2012.

[54] T. H. Haupt, J. Petersen, G. Ellekilde et al., "Plasma suPAR levels are associated with mortality, admission time, and Charlson Comorbidity Index in the acutely admitted medical patient: a prospective observational study," Critical Care, vol. 16, no. 4, article R130, 2012.

[55] B. Meijers, R. Poesen, K. Claes et al., "Soluble urokinase receptor is a biomarker of cardiovascular disease in chronic kidney disease," Kidney International, vol. 87, no. 1, pp. 210-216, 2015.

[56] G. I. Welsh and M. A. Saleem, "The podocyte cytoskeletonkey to a functioning glomerulus in health and disease," Nature Reviews Nephrology, vol. 8, no. 1, pp. 14-21, 2012.

[57] B. Zhang, W. Shi, J. Ma et al., “The calcineurin-NFAT pathway allows for urokinase receptor-mediated beta3 integrin signaling to cause podocyte injury," Journal of Molecular Medicine, vol. 90, no. 12, pp. 1407-1420, 2012.

[58] M.-J. Wu, C.-H. Chang, K.-H. Shu, H.-C. Ho, J.-R. Li, and Y.-C. $\mathrm{Fu}$, "Rapamycin promotes podocyte migration through the upregulation of urokinase receptor," Transplantation Proceedings, vol. 46, no. 4, pp. 1226-1228, 2014.

[59] J. Ma, B. Zhang, S. Liu et al., "1,25-dihydroxyvitamin D(3) inhibits podocyte uPAR expression and reduces proteinuria," PLoS ONE, vol. 8, no. 5, Article ID e64912, 2013.

[60] B. Zhang, S. Xie, W. Shi, and Y. Yang, "Amiloride off-target effect inhibits podocyte urokinase receptor expression and reduces proteinuria," Nephrology, Dialysis, Transplantation, vol. 27, no. 5, pp. 1746-1755, 2012.

[61] C.-C. Cheng, Y.-F. Lee, J.-L. Lan et al., "Mycophenolate mofetil alleviates lupus nephritis through urokinase receptor signaling in a mice model," Lupus, vol. 22, no. 6, pp. 554-561, 2013.

[62] A. Fornoni, J. Sageshima, C. Wei et al., "Rituximab targets podocytes in recurrent focal segmental glomerulosclerosis," Science Translational Medicine, vol. 3, no. 85, Article ID 85ra46, 2011.

[63] D. L. Veron, G. Villegas, P. K. Aggarwal et al., "Acute podocyte vascular endothelial growth factor (VEGF-A) knockdown disrupts alphavbeta3 integrin signaling in the glomerulus," PLoS ONE, vol. 7, no. 7, Article ID e40589, 2012. 
[64] M. J. Kemper, C. Wei, and J. Reiser, “Transmission of glomerular permeability factor soluble urokinase plasminogen activator receptor (suPAR) from a mother to child," American Journal of Kidney Diseases, vol. 61, no. 2, p. 352, 2013.

[65] N. Alachkar, C. Wei, L. J. Arend et al., "Podocyte effacement closely links to suPAR levels at time of posttransplantation focal segmental glomerulosclerosis occurrence and improves with therapy," Transplantation, vol. 96, no. 7, pp. 649-656, 2013.

[66] C. Morath, C. Wei, S. Macher-Goeppinger, V. Schwenger, M. Zeier, and J. Reiser, "Management of severe recurrent focal segmental glomerulosclerosis through circulating soluble urokinase receptor modification," American Journal of Therapeutics, vol. 20, no. 2, pp. 226-229, 2013.

[67] J. Huang, G. Liu, Y.-M. Zhang et al., "Urinary soluble urokinase receptor levels are elevated and pathogenic in patients with primary focal segmental glomerulosclerosis," BMC Medicine, vol. 12, article 81, 2014.

[68] D. Cathelin, S. Placier, M. Ploug et al., "Administration of recombinant soluble urokinase receptor per se is not sufficient to induce podocyte alterations and proteinuria in mice," Journal of the American Society of Nephrology, vol. 25, no. 8, pp. 16621668, 2014.

[69] R. J. H. Maas, J. F. M. Wetzels, and J. K. J. Deegens, "Serum suPAR concentrations in patients with focal segmental glomerulosclerosis with end-stage renal disease," Kidney International, vol. 85, no. 3, p. 711, 2014.

[70] T. Kitao, T. Kimata, E. Kanda et al., "Soluble urokinase receptor in a toddler with focal segmental glomerulosclerosis," Kidney International, vol. 86, no. 1, p. 208, 2014.

[71] E. Drucker and K. Krapfenbauer, "Pitfalls and limitations in translation from biomarker discovery to clinical utility in predictive and personalised medicine," EPMA Journal, vol. 4, article 7, 2013.

[72] J. P. A. Ioannidis, D. B. Allison, C. A. Ball et al., "Repeatability of published microarray gene expression analyses," Nature Genetics, vol. 41, no. 2, pp. 149-155, 2009.

[73] E. von Elm, D. G. Altman, M. Egger, S. J. Pocock, P. C. Gøtzsche, and J. P. Vandenbroucke, "The Strengthening the Reporting of Observational Studies in Epidemiology (STROBE) statement: guidelines for reporting observational studies," Annals of Internal Medicine, vol. 147, no. 8, pp. 573-577, 2007.

[74] C. Kilkenny, W. J. Browne, I. C. Cuthill, M. Emerson, and D. G. Altman, "Improving bioscience research reporting: the arrive guidelines for reporting animal research," PLoS Biology, vol. 8, no. 6, Article ID e1000412, 2010.

[75] R. J. H. Maas, J. K. J. Deegens, and J. F. M. Wetzels, "Serum suPAR in patients with FSGS: trash or treasure?" Pediatric Nephrology, vol. 28, no. 7, pp. 1041-1048, 2013.

[76] O. Slot, N. Brünner, H. Locht, P. Oxholm, and R. W. Stephens, "Soluble urokinase plasminogen activator receptor in plasma of patients with inflammatory rheumatic disorders: increased concentrations in rheumatoid arthritis," Annals of the Rheumatic Diseases, vol. 58, no. 8, pp. 488-492, 1999.

[77] J. A. Jefferson and C. E. Alpers, "Glomerular disease: 'suPAR'exciting times for FSGS," Nature Reviews Nephrology, vol. 9, no. 3, pp. 127-128, 2013.

[78] T.-H. Yoo, C. E. Pedigo, J. Guzman et al., "Sphingomyelinaselike phosphodiesterase $3 \mathrm{~b}$ expression levels determine podocyte injury phenotypes in glomerular disease," Journal of the American Society of Nephrology, vol. 26, no. 1, pp. 133-147, 2015.
[79] H. Trachtman, C. Wei, and J. Reiser, "Circulating factor in FSGS: a black sheep in the suPAR family?" Pediatric Nephrology, vol. 28, no. 7, pp. 1151-1152, 2013.

[80] D. Schlöndorff, "Are serum suPAR determinations by current ELISA methodology reliable diagnostic biomarkers for FSGS," Kidney International, vol. 85, no. 3, pp. 499-501, 2014.

[81] S. Sever, H. Trachtman, C. Wei, and J. Reiser, "Is there clinical value in measuring suPAR levels in FSGS?" Clinical Journal of the American Society of Nephrology, vol. 8, no. 8, pp. 1273-1275, 2013.

[82] R. Riisbro, I. J. Christensen, C. Høgdall, N. Brünner, and E. Høgdall, "Soluble urokinase plasminogen activator receptor measurements: influence of sample handling," International Journal of Biological Markers, vol. 16, no. 4, pp. 233-239, 2001.

[83] A. E. Schutte, A. Myburgh, M. H. Olsen, J. Eugen-Olsen, and R. Schutte, "Exploring soluble urokinase plasminogen activator receptor and its relationship with arterial stiffness in a bi-ethnic population: the SAfrEIC-study," Thrombosis Research, vol. 130, no. 2, pp. 273-277, 2012.

[84] B. Meijers and B. Sprangers, "The hype cycle for soluble urokinase receptor in FSGS: passing the trough of disillusionment?" Clinical Journal of the American Society of Nephrology, vol. 9, no. 11, pp. 1835-1836, 2014.

[85] L. Shen, G. Lu, N. Dong, L. Jiang, Z. Ma, and C. Ruan, "Von willebrand factor, ADAMTS13 activity, TNF- $\alpha$ and their relationships in patients with chronic kidney disease," Experimental and Therapeutic Medicine, vol. 3, no. 3, pp. 530-534, 2012.

[86] T. Takamatsu, N. Yasuda, T. Ohno, T. Kanoh, H. Uchino, and A. Fujisawa, "Soluble interleukin-2 receptors in the serum of patients with chronic renal failure," Tohoku Journal of Experimental Medicine, vol. 155, no. 4, pp. 343-347, 1988.

[87] R. J. Caruana, M. S. Leffell, S. A. Lobel, H. T. Campbell, and P. L. Cheek, "Chronic T-lymphocyte activation in chronic renal failure: a study of hemodialysis, CAPD and pre-dialysis patients," International Journal of Artificial Organs, vol. 15, no. 2, pp. 93-98, 1992.

[88] G. Almroth, J. Lönn, F. Uhlin et al., "Fibroblast growth factor 23 , hepatocyte growth factor, interleukin-6, high-sensitivity Creactive protein and soluble urokinase plasminogen activator receptor. inflammation markers in chronic haemodialysis patients?" Scandinavian Journal of Immunology, vol. 78, no. 3, pp. 285-290, 2013.

[89] A. Segarra, E. Jatem, M. T. Quiles et al., "Value of soluble urokinase receptor serum levels in the differential diagnosis between idiopathic and secondary focal segmental glomerulosclerosis," Nefrologia, vol. 34, no. 1, pp. 53-61, 2014.

[90] T. C. Jungraithmayr, K. Hofer, P. Cochat et al., "Screening for NPHS2 mutations may help predict FSGS recurrence after transplantation," Journal of the American Society of Nephrology, vol. 22, no. 3, pp. 579-585, 2011.

[91] A. Vasudevan, A. Siji, A. Raghavendra, T. S. Sridhar, and K. D. Phadke, "NPHS2 mutations in Indian children with sporadic early steroid resistant nephrotic syndrome," Indian Pediatrics, vol. 49, no. 3, pp. 231-233, 2012.

[92] S. Weber and B. Tönshoff, "Recurrence of focal-segmental glomerulosclerosis in children after renal transplantation: clinical and genetic aspects," Transplantation, vol. 80, supplement 1 , pp. S128-S134, 2005.

[93] R. Bertelli, F. Ginevri, G. Caridi et al., "Recurrence of focal segmental glomerulosclerosis after renal transplantation in patients with mutations of podocin," American Journal of Kidney Diseases, vol. 41, no. 6, pp. 1314-1321, 2003. 
[94] J. Gellermann, F. Schaefer, and U. Querfeld, "Serum suPAR levels are modulated by immunosuppressive therapy of minimal change nephrotic syndrome," Pediatric Nephrology, vol. 29, no. 12, pp. 2411-2414, 2014.

[95] O. Andersen, J. Eugen-Olsen, K. Kofoed, J. Iversen, and S. B. Haugaard, "Soluble urokinase plasminogen activator receptor is a marker of dysmetabolism in HIV-infected patients receiving highly active antiretroviral therapy," Journal of Medical Virology, vol. 80, no. 2, pp. 209-216, 2008.

[96] S. R. Ostrowski, T. L. Katzenstein, M. Pedersen et al., "Plasma levels of intact and cleaved urokinase receptor decrease in HIV-1-infected patients initiating highly active antiretroviral therapy," Scandinavian Journal of Immunology, vol. 63, no. 6, pp. 478-486, 2006.

[97] S. J. Park, M. A. Saleem, and J. I. Shin, "Elevated soluble urokinase receptors in focal segmental glomerulosclerosis: a role for IL-2?” Kidney International, vol. 85, no. 6, pp. 1469-1470, 2014.

[98] P. F. Piguet, C. Vesin, Y. Donati, F. Tacchini-Cottier, D. Belin, and C. Barazzone, "Urokinase receptor (uPAR, CD87) is a platelet receptor important for kinetics and TNF-induced endothelial adhesion in mice," Circulation, vol. 99, no. 25, pp. 33153321, 1999.

[99] M. Delville, T. K. Sigdel, C. Wei et al., "A circulating antibody panel for pretransplant prediction of FSGS recurrence after kidney transplantation," Science Translational Medicine, vol. 6, no. 256, Article ID 256ra136, 2014.

[100] S. Shishido, H. Satou, M. Muramatsu et al., "Combination of pulse methylprednisolone infusions with cyclosporine-based immunosuppression is safe and effective to treat recurrent focal segmental glomerulosclerosis after pediatric kidney transplantation," Clinical Transplantation, vol. 27, no. 2, pp. E143-E150, 2013.

[101] M. Bitzan, S. Babayeva, A. Vasudevan, P. Goodyer, and E. Torban, "TNF $\alpha$ pathway blockade ameliorates toxic effects of FSGS plasma on podocyte cytoskeleton and $\beta 3$ integrin activation," Pediatric Nephrology, vol. 27, no. 12, pp. 2217-2226, 2012.

[102] M. A. Saleem, "The phenomenon of focal segmental glomerulosclerosis post-transplantation-a one-hit wonder?" Pediatric Nephrology, vol. 27, no. 12, pp. 2163-2166, 2012.

[103] C. Faul, M. Donnelly, S. Merscher-Gomez et al., "The actin cytoskeleton of kidney podocytes is a direct target of the antiproteinuric effect of cyclosporine A," Nature Medicine, vol. 14, no. 9, pp. 931-938, 2008.

[104] A. Kronbichler and A. Bruchfeld, "Rituximab in adult minimal change disease and focal segmental glomerulosclerosis," Nephron-Clinical Practice, vol. 128, no. 3-4, pp. 277-282, 2014.

[105] A. Kronbichler, J. Kerschbaum, G. Fernandez-Fresnedo et al., "Rituximab treatment for relapsing minimal change disease and focal segmental glomerulosclerosis: a systematic review," American Journal of Nephrology, vol. 39, no. 4, pp. 322-330, 2014.

[106] J. I. Shin and A. Kronbichler, "Rituximab for patients with nephrotic syndrome," The Lancet, vol. 385, no. 9964, pp. 225226, 2015. 


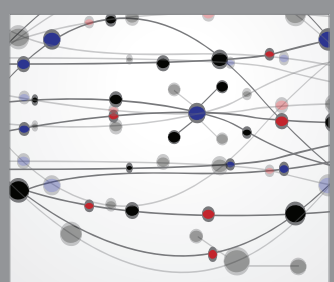

The Scientific World Journal
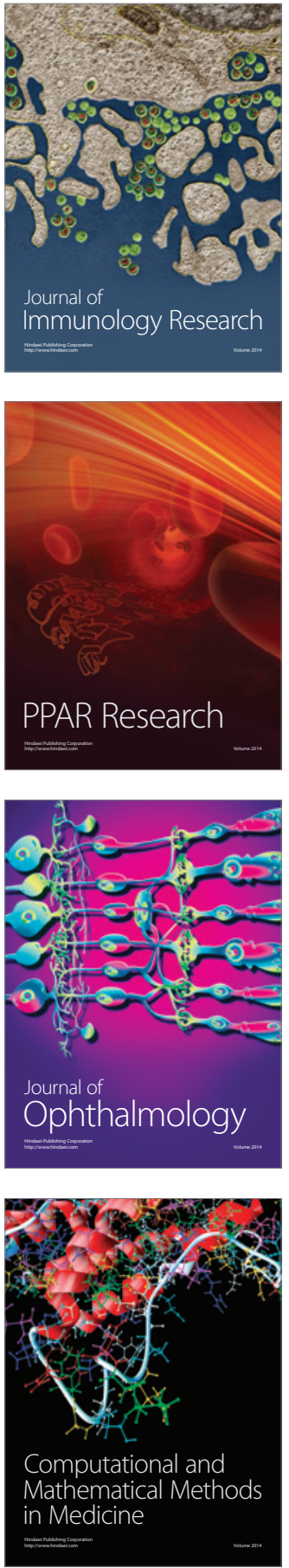

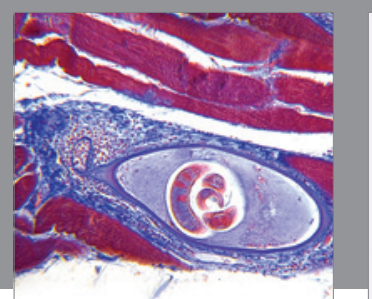

Gastroenterology Research and Practice

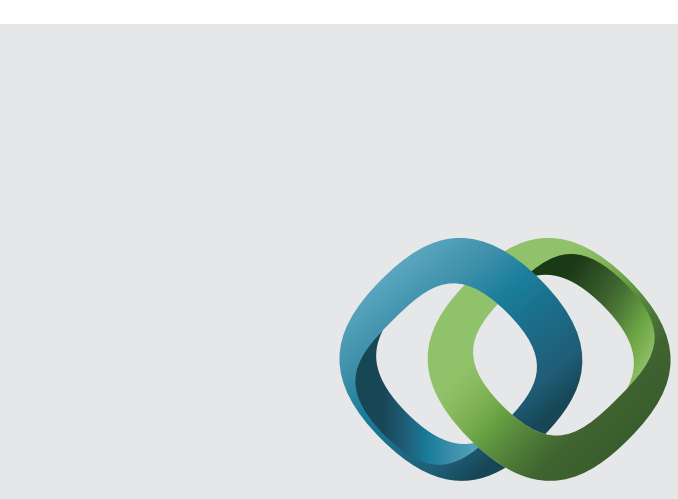

\section{Hindawi}

Submit your manuscripts at

http://www.hindawi.com
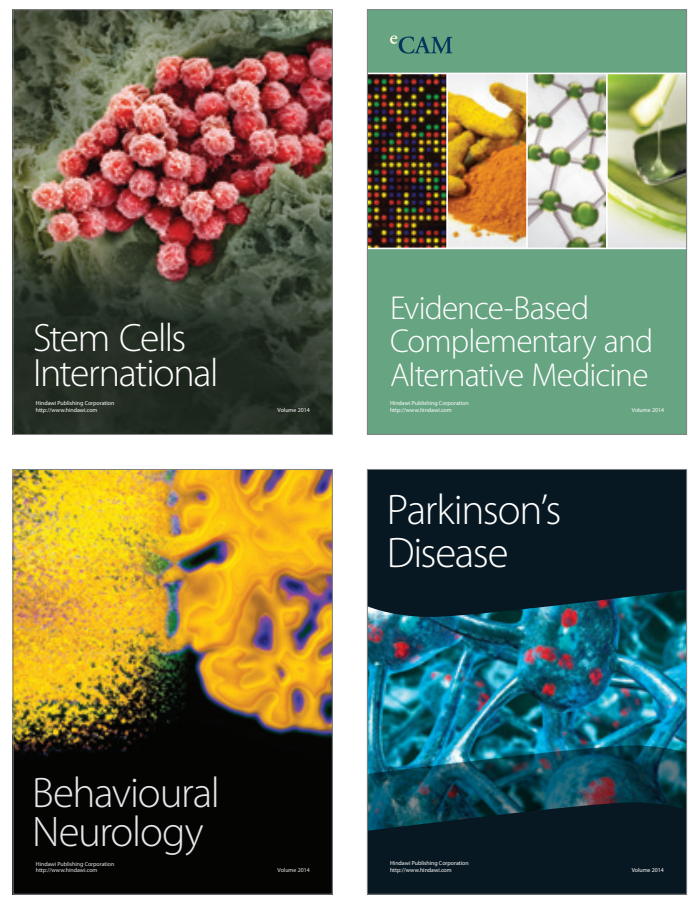
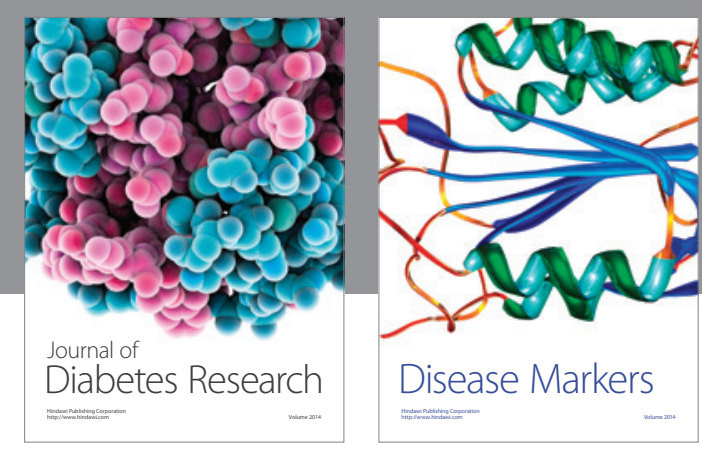

Disease Markers
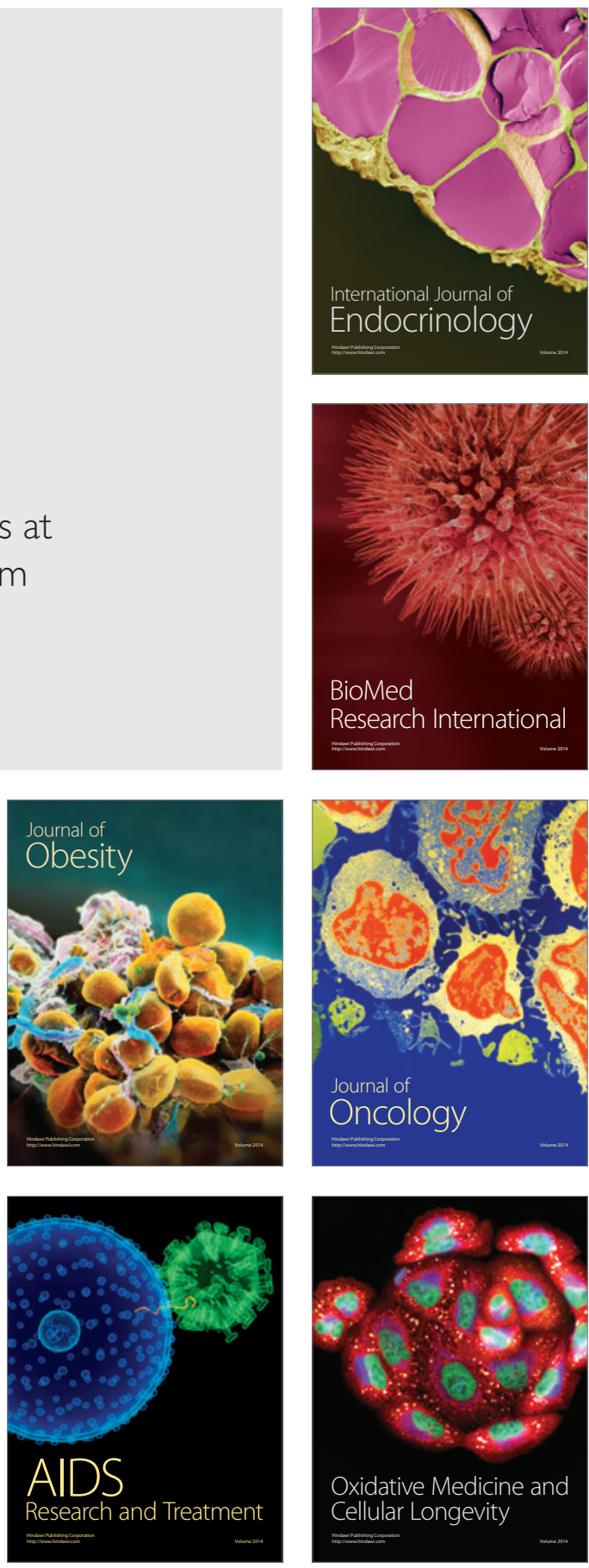